\title{
CURSO DE EDUCAÇÃO DO CAMPO COM FORMAÇÃO FREIREANA E O ENSINO DE LIBRAS
}

\author{
Field Education course with freirean education for teaching libras
}

\section{Carrera de Educación para el Campo con formación freireana y la enseñanza de libras}

\author{
Waldma Maíra Menezes de Oliveira \\ Ivanilde Apoluceno de Oliveira ${ }^{2}$
}

\begin{abstract}
Resumo
Este trabalho objetiva analisar as Representações Sociais que graduandos do Curso de Licenciatura em Educação do Campo - LEDOC-UFPA-BRASIL possuem sobre a prática pedagógica da professora de Libras e como estas representações expressam a contribuição da disciplina de Libras à formação freireana na educação do campo, considerando que a educação de Paulo Freire é o principal referencial teórico do curso. Trata-se de uma pesquisa qualitativa, cujos sujeitos foram 28 estudantes de graduação. A coleta de dados foi inspirada na associação livre de palavras e os dados organizados e analisados por meio da técnica da Análise de Conteúdos, tendo por base a abordagem processual de Serge Moscovici. Entre os resultados destaca-se que as representações dos educandos sobre a ação educativa da professora evidenciaram existir os seguintes princípios freireanos: a) o diálogo, por meio da Roda de Conversa e de ação dialógica através da Libras, b) a práxis, por meio do ensino crítico-reflexivo, envolvendo o debate e a representatividade do movimento surdo, bem como o reconhecimento da Libras como elemento formativo da identidade surda e c) o respeito às diferenças, com a criação de ambiente de alteridade, reconhecendo os sujeitos e seus saberes, constituindo-se em uma prática educativa humanizadora e acolhedora.
\end{abstract}

PALAVRAS-CHAVE: Educação do Campo. Libras. Representações Sociais.

\begin{abstract}
This paper aims to analyze the Social Representations that undergraduate students of Field Education course possess about the pedagogical practice of a sign language teacher and how these representations express the contribution of the sign language discipline to the education based on Freiriana formation. The work presents a qualitative investigation, whose subjects were 28 undergraduate students. The data collection was inspired in the free association of words and these data were organized and analyzed using the content analysis technique with

\footnotetext{
${ }^{1}$ Doutoranda e Mestra em Educação pela Universidade do Estado do Pará. Professora de Libras da Universidade Federal do Pará. Endereço profissional: Trav. Pe. Antônio Franco, 2617 - Bairro da Matinha, 68400-000. Cametá-Pará. E-mail: waldmamaira@ hotmail.com. Orcid: https://orcid.org/00000002-8747-5185

${ }^{2}$ Doutora em Educação pela Pontifícia Universidade Católica de São Paulo. Professora Titular da Universidade do Estado do Pará. Endereço profissional: Rua do Una, 156, Telégrafo, 66050-540, Belém Pará. E-mail: nildeapoluceno@uol.com.br. Orcid: https://orcid.org/0000-0002-3458-584X
} 
emphasis on categorization, i.e., considering the procedural approach of Sergi Moscovici. Among all results it is highlighted that the students' representation about the educational actions applied by the teacher are indicating the presence of the following Freiriano's principles: a) the dialogue through conversation circle and signal languages, b) Praxis through critical-reflective teaching considering the debate and representation of deaf movement and the recognition of the sign language as a formative element in the deaf identity and c) The respect about the differences with the discussion about one environment of alterity, respecting the subjects and their knowledge in order to build the teaching based on a educative practice that is humanized and cozy.

KEYWORDS: Rural Education. Signal Language. Social Representations.

\section{Resumen}

El presente trabajo tiene como objetivo analizar las Representaciones Sociales que los estudiantes de la Carrera de Licenciatura en Educación para el Campo - LEDOC (en sus siglas en portugués) - UFPA - BRASIL tienen sobre la practica pedagógica de la profesora de Libras. Asimismo, tienen como objetivo reconocer como estas representaciones expresan la contribución de la disciplina de Libras a la formación freireana en la educación para el campo, considerando que la educación de Paulo Freire es el principal referencial teórico de esta carrera. Este estudio trata de una investigación cualitativa, cuyos sujetos analizados fueron 28 estudiantes. La colecta de datos fue inspirada en la asociación libre de palabras, los datos fueron organizados y analizados por medio de la técnica de Análisis de Contenido, teniendo como base el abordaje procesual de Serge Moscovici. Entre los resultados se destaca que, las representaciones de los estudiantes sobre la acción educativa de la profesora pusieron en evidencia que existen los siguientes principios freireanos: a) el diálogo, a través de Ruedas de Dialogo y de la acción dialógica mediante la lengua Libras, b) la praxis, a través de la enseñanza crítico-reflexiva, promoviendo el debate y la representatividad del movimiento de personas con sordera, así como el reconocimiento de la lengua Libras como elemento formativo de la identidad sorda y c) el respeto a las diferencias, con la creación de ambiente de alteridad, reconociendo los sujetos y sus saberes, constituyéndose en una práctica educativa humanizadora y acogedora.

PALABRAS CLAVE: Educación para el Campo. Libras. Representaciones Sociales.

\section{INTRODUÇÃO}

O Curso de Licenciatura em Educação do Campo (LEDOC) do Campus Universitário do Tocantins/Cametá, da Universidade Federal do Pará - UFPA tem por base o pensamento educacional de Paulo Freire e faz uma interface com a Educação Especial por meio da oferta da Libras, que é uma disciplina obrigatória em todos os cursos de licenciatura no Brasil (2005). Segundo o Projeto Pedagógico do Curso - PPC, a disciplina Língua Brasileira de Sinais - Libras é obrigatória, correspondendo à $68 \mathrm{~h}$, com base no cumprimento legal (BRASIL, 2005).

Com a implantação da Libras nos cursos de formação de professores, espera-se que o processo de inclusão seja praticado com mais eficiência, haja vista que os futuros docentes por terem acesso ao conhecimento sobre a história dos surdos e os aspectos 
teóricos da língua, podem atuar positivamente na construção do conhecimento dos discente, além de facilitar a comunicação entre alunos e professores.

A disciplina de Libras foi ministrada no Curso, nos meses de abril e maio de 2018, por uma professora do quadro docente da UFPA. A pesquisa foi elaborada com base em uma pesquisa de campo, de abordagem qualitativa, com ênfase na Teoria das Representações Sociais realizada com educandos do LEDOC-UFPA, com o foco em duas problemáticas: (1) que Representações Sociais (RS) os graduandos do LEDOCUFPA possuem sobre a prática pedagógica da professora de Libras? (2) Estas representações sobre a prática pedagógica da Libras evidenciam que a disciplina contribui para a formação freireana na educação do campo?

Os objetivos deste estudo são analisar as Representações Sociais de graduandos da LEDOC-UFPA sobre a prática pedagógica da professora de Libras e verificar a contribuição da disciplina Libras na formação freireana da educação do campo.

O estudo fundamentou-se em fontes como Brasil (2005) e autores, entre os quais: Freire (1980a, 1980b, 1981,1987, 1993, 1994, 2004, 2007), Lopes (2007) e Moscovici (1981, 2009).

Inicialmente apresenta-se a disciplina de Libras na Educação do Campo e, em seguida, a metodologia, e, por fim, as práticas pedagógicas freireanas no ensino de Libras.

\section{A disciplina de Libras na Educação do Campo}

No campo da surdez, as políticas linguísticas e formativas são descritas, principalmente, pela Lei de Libras $\mathrm{n}^{\mathbf{0}} 10.436$, de 24 de abril de 2002, e pelo Decreto $\mathrm{n}^{\mathbf{o}}$ 5.626, de 22 de dezembro de 2005, o qual legitima a Lei de Libras. A Lei $\mathrm{n}^{\circ} 10.436$ destaca que:

\footnotetext{
Entende-se como Língua Brasileira de Sinais - Libras - a forma de comunicação e expressão, em que o sistema linguístico de natureza visual motora, com estrutura gramatical própria, constitui um sistema linguístico de transmissão de ideias e fatos, oriundos de comunidades de pessoas surdas do Brasil (BRASIL, 2002, p. 1).
}

A Libras, ao ser reconhecida como língua pertencente à comunidade Surda, afirma-se "como instrumento cultural" (LOPES, 2007, p. 28). A política linguística no campo da Libras tem por referência o Decreto $\mathrm{n}^{\circ}$ 5.626/05, de 22 de dezembro de 2005, que regulamenta a Lei de Libras $n^{\circ} 10.426 / 02$ e reafirma ser esta a língua natural do sujeito surdo, demarcando o início de implantações desta política na área da inclusão educacional, social, linguística e saúde.

O Decreto $n^{\circ}$ 5.626/2005 versa sobre as medidas destinadas para a formação de profissionais para atuação com sujeitos surdos como: professores bilíngues; professores de Libras e de Língua Portuguesa como L2 para surdos; instrutores e intérpretes de Libras. Nesse sentido, destacamos neste artigo dois pontos importantes do Decreto: a implementação da Libras como disciplina obrigatória nos cursos de licenciatura e o instrutor de Libras. Esse decreto, também, destaca a inclusão da Libras como disciplina curricular nos cursos de formação de professores. No Art. $3^{\circ}$ estabelece que:

A Libras deve ser inserida como disciplina curricular obrigatória nos cursos de formação de professores para o exercício do magistério, em nível médio e superior, e nos cursos de Fonoaudiologia, de instituições de ensino, públicas 
e privadas, do sistema federal de ensino e dos sistemas de ensino dos Estados, do Distrito Federal e dos Municípios (BRASIL, 2005, p.1).

O marco da inserção de disciplinas sobre a educação especial nos currículos de formação docente, neste caso a Educação dos Surdos, deu-se após a promulgação da Lei $\mathrm{n}^{\mathrm{o}}$ 10.436, que reconhece a Libras como língua oficial dos surdos. Em seu Art. $4^{\mathrm{o}}$, expressa a obrigatoriedade de as instituições de formação docente inserir em seus currículos a disciplina Libras.

Com a implantação da Libras nos cursos de formação de professor, espera-se que o processo de inclusão seja praticado com mais eficiência, haja visto que os futuros docentes terão conhecimento sobre a história dos surdos e os aspectos teóricos da língua, podendo atuar positivamente na construção do conhecimento dos discentes, além de facilitar a comunicação entre alunos e professores. Assim, a implantação da disciplina de Libras nos cursos de licenciatura tem como medida formar profissionais mais inclusivos e com olhares holísticos acerca da diferença surda. O Curso de Licenciatura em Educação do Campo do Campus Universitário do Tocantins/Cametá apresenta no seu PPC a disciplina obrigatória Língua Brasileira de Sinais - Libras (68h) e a disciplina eletiva Educação Inclusiva e Direitos Humanos (45h) na formação inicial dos graduandos.

Pensa-se a disciplina de Libras para além do ensino de vocabulários, aspectos legais e históricos da surdez, mas principalmente nos aspectos culturais, sociais e regionais dos surdos que vivem na Amazônia. Desta forma, o estudo traz a discussão do ser humano na sua cultura respeitando suas crenças, respeitando as diferenças e valorizando os saberes dos diversos segmentos culturais surdos. Tal formação fala de eticidade, de gênero, de língua, que é falar do ser humano, contextualizado em uma cultura em processo de construção.

Por tanto, a disciplina coloca o sujeito surdo no centro do debate, articula-se a sua línguaa sua cultura ribeirinha e chama o movimento social surdo para sala de aula. Tal ação oportuniza os movimentos sociais, isto é, à pessoa surda, que foi historicamente negada pelo seu corpo deficiente, pela sua língua, enquanto língua subalterna e sujeito amazônico: o direitode dizer sua palavra, a sua verdade e de se firmar no cenário nacional enquanto um ser social, mediante a sua integralidade existencial, social, cultural e linguística.

A disciplina apresenta uma concepção ética, política e educativa em relação ao outro surdo, enquanto ser criador, fazedor e recriador de cultura, na qual está presente nas sementes da práxis freireana, as quais hoje se materializam na interface da Educação do Campo com a Educação Especial.

A interface entre a Educação Especial e a Educação do Campo está presente em vários documentos, como: as Diretrizes Operacionais para a Educação Básica nas Escolas do Campo (BRASIL, 2002), a Política Nacional de Educação Especial na Perspectiva da Educação Inclusiva (BRASIL, 2008a) a Resolução 2/2008 (BRASIL, 2008b).

No primeiro documento, no art $2^{\circ}$, as Diretrizes, com base na legislação educacional, constituem um conjunto de princípios e de procedimentos que visam a adequar o projeto institucional das escolas do campo às Diretrizes Curriculares Nacionais para a Educação de Jovens e Adultos, a Educação Especial, a Educação Indígena, a Educação Profissional de Nível Técnico e a Formação de Professores em Nível Médio na modalidade Normal. (BRASIL, 2002). 
No segundo documento legal, "a interface da educação especial na educação indígena, do campo e quilombola deve assegurar que os recursos, serviços e atendimento educacional especializado estejam presentes nos projetos pedagógicos construídos com base nas diferenças socioculturais desses grupos" (BRASIL, 2008a, p.17). E por fim, no terceiro:

\begin{abstract}
$\S 5^{\circ}$ Os sistemas de ensino adotarão providências para que as crianças e os jovens portadores de necessidades especiais, objeto da modalidade de Educação Especial, residentes no campo, também tenham acesso à Educação Básica, preferentemente em escolas comuns da rede de ensino regular (BRASIL, 2008b)
\end{abstract}

Assim, a Educação do Campo e a Educação Especial são hoje áreas que se tornam cada vez mais próximas, ambas lutam por direitos sociais, educacionais, identitários e linguísticos. Ao falar dessas duas minorias sociais - não em questão quantitativa, mas sim por questões políticas- necessita-se pensar a formação inicial do profissional que irá atender está clientela, ou seja, pensar a formação dos graduandos da licenciatura em Educação do Campo.

Pelo Projeto Pedagógico do Curso - PPC a disciplina Língua Brasileira de Sinais - Libras corresponde às 68h. Assim, o discente terá apenas 1 (uma) disciplina para trabalhar questões sobre a Língua Brasileira de Sinais. De acordo com Santos e Campos (2013, p. 242)

\footnotetext{
A disciplina apresenta como objetivo, inclusive no texto da Lei, uma melhor formação de professores para a atuação em salas de aula inclusivas que, possivelmente, terão a presença de alunos com os mais diversos tipos de deficiência, incluindo a surdez.
}

Com a implantação da Libras nos cursos de formação de professores, espera-se que o processo de inclusão seja praticado com mais eficiência, já que os docentes terão conhecimentos sobre toda a história dos surdos e os aspectos teóricos da língua, e espera-se com isso, que possam atuar positivamente na construção do conhecimento dos discente, além de facilitar a comunicação entre alunos e professores.

\title{
Metodologia
}

Nesta investigação, realizou-se uma pesquisa de campo de abordagem qualitativa que "parte do fundamento de que há uma relação dinâmica entre o mundo real e o sujeito, uma interdependência viva entre o sujeito e o objeto, um vínculo indissociável entre o mundo objetivo e a subjetividade do sujeito" (CHIZZOTTI, 2009, p. 79).

Este estudo tem por base a Teoria das Representações Sociais, com o foco na educação inclusiva e nas representações dos alunos universitários sobre a prática pedagógica da professora de Libras, isto é, na maneira em que elaboram e partilham simbologias significantes e construtivas acerca dessa prática.

$\mathrm{Na}$ análise das Representações Sociais sobre educação de surdos, utilizou-se a abordagem processual, desenvolvida por Moscovici (1981; 2009), que visa "conhecer os processos de formação de uma representação social com o objetivo de buscar suas condições sociais de produção assim como as práticas sociais que as geram e as justificam" (ALVES-MOZZOTI; MAIA; MAGALHÃES, 2010, p. 5). 
A Representação Social é entendida como "forma de conhecimento prático, de senso comum, que circula na sociedade. Esse conhecimento é constituído de conceitos e imagens sobre pessoas, papeis e fenômenos do cotidiano" (RANGEL, 2004, p. 66).

Os processos de formação das Representações Sociais, na visão de Moscovici (2009), compreendem a Ancoragem e a Objetivação, os quais fomentam a construção do núcleo figurativo, que, por sua vez, é constituído estruturas figurativas e simbólicas.

Nascimento (2013, p. 52 e 50) explica que:

\begin{abstract}
a ancoragem é atribuição pela sociedade de uma escala de valores e preferências para um objeto social em função das interações sociais. [...] a objetivação pode-se ser vista nesse processo de formação das representações sociais como um recurso que o pensamento utiliza, denominado de naturalização, para tornar concretos, reais, conceitos abstratos.
\end{abstract}

Como coleta de dados inspirou-se na associação livre de palavras, que consiste numa técnica projetiva, capaz de "evidenciar as representações de um indivíduo acerca do objeto indutor" (COUTINHO; NÓBREGA; CATÃO, 2003, p. 51).

Os participantes da pesquisa foram 28 graduandos da Universidade Federal do Pará do Campus Cametá polo Igarapé - Miri, que fizeram a disciplina de Libras, no período de 25 de abril a 12 de maio de 2018. Os entrevistados assinaram o Termo de Consentimento Livre e Esclarecido (TCLE) permitindo a publicação de informações. Assim, os entrevistados estão codificados de E1 a E28.

$\mathrm{Na}$ sistematização e análise dos dadosutilizaram-se técnicas da Análise de Conteúdos de Bardin (2010) e trabalhou-se "o material acumulado, buscando destacar os principais achados da pesquisa" (LUDKE; ANDRÉ, 1986, p. 48), criando-se categorias temáticas, que viabilizaram a organização deste trabalho e possibilitam ao leitor um olhar mais holístico e humanizador sobre a prática educativa da professora de Libras em relação à Surdez.

\title{
Práticas Pedagógicas Freireanas no ensino de Libras
}

A educação de Paulo Freire é constituída por uma lógica do pensar-sentir dialogado, compreendendo o ser humano na inteireza do seu ser, ser de razão, sentimentos e amorosidade, que contribui ao processo de emancipação humana.

A dialogicidade é também uma forma de promover o exercício da ação docente, que pressupõe uma responsabilidade ética e política em relação aos educandos, tendo como princípio a construção da ação pedagógica humanizadora. Perpassa pelo exercício do respeito e da tolerância como elementos para a efetivação da convivência com o diferente, prática esta que não pode estar de acordo com o discurso neoliberal que nega a historicidade humana (FREIRE, 2007).

A prática da professora de Libras, a partir da fala dos entrevistados, foi sistematizada nas categorias temáticas freireanas, explicitadas a seguir.

\section{Dialogicidade e a amorosidade na prática educativa}

Ao serem questionados, sobre a prática educativa da professora de Libras, os discentes ancoram suas representações nas categorias fundantes freireanas: diálogo $e$ amorosidade, atribuindo a essas categorias as seguintes ancoragens: coletiva, boa, 
compreensiva e acolhedora, conforme quadro a seguir. As objetivações estão expressas em suas falas.

\section{a) Coletiva e Boa}

Para E5 a prática dialógica se manifesta na coletividade, na participação e na troca de saberes, segundo E7 e E8, nas rodas de conversa e E15 pelo diálogo.

Porque envolve a todos. Ela não se individualiza, usa métodos na coletividade. Em que todos nós participamos, dialogamos e trocamos saberes (E5).

Porque ela utiliza de uma metodologia, onde ela busca interagir com os discentes, fazendo rodas de conversas, utiliza Datashow para o ensino (E7)

Porque ela utiliza várias metodologias, com: Roda de Conversa, slides, teoria atrelada a prática (E8).

Ela utiliza o diálogo com os alunos através de roda de conversa, tem uma metodologia bastante flexível (E15). educativa.

Assim, para os dois entrevistados a dialogicidade estaria presente na prática

Freire (1980a, p.43) define o diálogo como "o encontro amoroso dos homens que, mediatizados pelo mundo, o pronunciam, isto é, o transformam, e transformando-o, o humanizam para a humanização de todos". Nessa relação de comunicação, estariam presentes: a Professora de Libras e os discentes da licenciatura em Educação do Campo.

\section{b) Compreensiva e acolhedora}

E24 retrata a relação acolhedora que a professora oportuniza aos alunos para a aprendizagem: "Porque todos participam de forma harmoniosa, todos conseguem interagir. Todos se sentem à vontade e bem acolhidos". Para E27 "a professora faz e fez com que todos consigam compreender sobre o surdo, sobre a Libras com calma e paciência". Portanto, as palavras: harmonia, paciência e acolhimento seriam raízes da amorosidade presente no fazer docente.

Desta forma, aamorosidade está presente na prática educativa enquanto princípio formativo do saber-fazer docente. A amorosidade é compreendida por Freire (1981, p.29) "como uma intercomunicação íntima de duas consciências que se respeitam", na medida em que o ser humano, como ser dialógico, cuja busca de ser mais se materializa por meio da comunicação e do afeto com outros sujeitos.

Percebe-se nas falas dos entrevistados que a prática educativa da professora de Libras está ancorada nos princípios formativos de uma educação libertadora, isto é, no fazer docente dialógico, no respeito ao outro, na autonomia e a valorização dos saberes dos educandos, na construção de um saber coletivo, humanizador e holístico sobre o outro (Surdo) e a sua Língua (Libras).

\section{Alteridade no fazer docente} Alteridade.

Os entrevistados ancoraram o fazer docente da professora de Libras na

Os entrevistados atribuíram à categoria Alteridade as seguintes ancoragens: reflexiva, inovadora, valorização, inclusiva e inovadora. 


\section{a) Reflexiva crítica} a professora:

Os estudantes objetivaram a representação como reflexiva crítica ao afirmar que

nos faz pensar a respeito da Língua Brasileira de Sinais como necessária para se aprender e promover a inclusão do aluno surdo, além disso nos possibilita uma reflexão nova que o surdo é capaz e não incapaz como pensava antes. (E9)

utiliza-se de recursos reflexivos, em que busca instigar de nós alunos um outro olhar para o sujeito surdo, sendo um sujeito de direitos e deveres (E25).

Utiliza filmes, vídeos, etc isso nos leva a refletir muito sobre a questão do surdo (E15).

\section{b) Inovadora}

A inovação aparece objetivada por E12, E28 e E23 pela eficácia e forma de ensinar que possibilitaram a aprendizagem dos estudantes e compreender melhor a educação da pessoa surda.

Porque ela [faz] o educando sentir-se ativo e capaz de aprender conteúdos repassados de maneira leve e eficaz, visto que suas inovações se adaptam com a realidade do aluno (E12).

Como é o primeiro contato com a língua de sinais, a professora inovou as aulas, trazendo a representação da comunidade surda para a sala, os diálogos criados ajudaram na compreensão e aprendizagem dos sinais para facilitar a comunicação com surdos (E28).

Porque a professora faz uso de procedimentos que são de suma importância para nós, enquanto discentes, que estamos iniciando a compreender a realidade desses alunos (E23).

Porque ela demonstrou a transformação de uma aula de Libras antes e hoje (E20).

\section{c) Valorativa e Inclusiva}

O fato da professora "valorizar a comunidade surda, respeitando características e valores que cada indivíduo possui dentro da sociedade" foi apontado por E16 como uma educação inclusiva. E E11 considera que a professora promove um espaço inclusivo.

Porque ela utiliza métodos que facilita a aprendizagem tanto do aluno ouvinte (nós) e dos surdos (comunidade surda que veio para sala) e buscar relacionar entre ambos a realidade de um espaço inclusivo (E11).

Assim, os estudantes destacam em sua fala que a professora trabalha o ensino de Libras com base na Alteridade, pois possibilita aos alunos um novo olhar sobre o sujeito surdo, partindo da diferença linguística e não da deficiência.

O fazer docente, no princípio freireano, parte da premissa que o ensinar estaria interligado ao respeito, a alteridade e ao diálogo, tendo os alunos e docentes o direito de dizer a palavra e, assim, partilhar e construir novos saberes. Freire (1993, p.27) descreve que:

[...] ]ensinar e aprender se vão dando de tal maneira que quem ensina aprende, de um lado, porque reconhece um conhecimento antes aprendido e, de outro, porque, observando a maneira como a curiosidade do aluno aprendiz trabalha 
para apreender $[\ldots]$, o ensinante se ajuda a descobrir incertezas, acertos, equívocos.

No processo de ensino aprendizagem o professor e aluno são sujeitos do conhecimento e aprendentes. Na ação educativa há partilha de saberes, porque, para Freire (1993) todos sabemos alguma coisa, temos nossa leitura de mundo e experiências de vida. Dessa maneira, a alteridade deve ser base na construção da prática educativa, já que possibilita a percepção e a participação do outro no processo educativo. Falar de alteridade é falar de diferença, respeito, responsabilidade para com o outro, é perceber o "outro" por sua diferença e não como inferior (FREIRE, 2004).

A prática educativa da professora de Libras, então, oportuniza aos discentes representar o surdo pela sua diferença, pela sua singularidade linguística e identitária elementos esses enraizados na premissa da Alteridade.

\section{Praxiológica e Engajada}

Ao serem questionados sobre o fazer educativo da professora de Libras os entrevistados ancoraram suas Representações Sociais (RS) na: Dinâmica,Práxis, $e$ Abrangente eEngajamento político.

\section{a) Dinâmica e práxis}

Os estudantes objetivaram suas representações enfatizando serem as aulas dinâmicas e que relacionam a teoria e a prática, a reflexão e a ação (práxis).

\footnotetext{
Porque é uma prática que envolve os alunos fazendo a dinâmica entre teoria e prática, em que usando essa metodologia a aula não fica cansativa e repetitiva(E1).

Porque ela consegue mostrar a teoria e a prática juntas. Ela chama os surdos daqui para dialogarmos. Promove uma prática bilíngue (E3).

Utilizou da praxiologia trazendo para a sala de aula representatividade surda, protagonismo surdo e etc (E7).

Porque trouxe a prática com a teoria, ou seja, representatividade surda para a sala de aula, que facilitou a compreensão no processo de ensino aprendizagem, as aulas foram diferenciadas com práticas pedagógicas inovadoras (E18).

Porque integra a teoria e a prática, trazendo surdos para sala de aula nos possibilita entender melhor a realidade deles (E22).

Porque dialoga entre a ação e a reflexão, instiga para a busca e a compreensão de novos conhecimentos acerca da comunidade surda, da língua de sinais (E17).
}

\section{b) Abrangência e Engajamento político}

Os estudantes apontaram em suas falas objetivações que representam ser um ensino abrangente porque trata da inclusão como um todo, apesar do foco na surdez, e um engajamento político com os povos do campo, tendo um envolvimento com a comunidade surda, por isso a preocupação com a prática, além da teoria.

Abrange o universo da inclusão como um todo. Buscando métodos pedagógicos para desenvolver uma educação diferenciada para os povos do campo. (E17) 


\begin{abstract}
Além das aulas expositivas foi ilustrada em termos práticos a atuação do intérprete e do instrutor de Libras (E10)

Pois podemos observar que a mesma tem práticas com a comunidade surda (E15)
\end{abstract}

Desta forma, na visão dos entrevistados a professora materializa uma prática educativa engajada politicamente com a educação de surdo, por trazer para a sala de aula a comunidade surda, promovendo uma educação bilíngue.

A práxis é entendida por Freire (1987, p.38 e 122) como "reflexão e ação dos homens sobre o mundo para transformá-lo. Sem ela, é impossível a superação da contradição opressor-oprimido [...] O seu quefazer, ação e reflexão, não pode dar-se sem a ação e a reflexão dos outros, se seu compromisso é o da liberdade". Desse modo, o educador no seu fazer educativo deve embasar-se em um ensino reflexivo e que promova o respeito às diferenças.

A práxis, também, possibilita uma maior reflexão na formação dos educadores, "sem a qual a teoria pode ir virando blábláblá e a prática, ativismo" (FREIRE, 2007, p. 24). É, um elemento importantíssimo para materialização da práxis é a criticidade. Para Freire (2007), a crítica é a curiosidade epistemológica, resultante da transformação da curiosidade ingênua em crítica.

Assim, ao trazer a comunidade surda para a sala de aula, a professora de Libras oportuniza aos educandos o contato com a diferença, para além dos textos acadêmicos e de suas falas, efetivando um encontro autentico com o outro e com suas especificidades. Ao falar de Surdez a professora de Libras proporciona aos educandos a vivência na práxis, do respeito deste outro e de sua língua, o que acarreta, aos educandos, uma nova representação, o surdo começa a ser visto enquanto um grupo político, identitário e linguístico presente na sociedade. Tal visão enfatiza que:

\footnotetext{
Não há uma forma única de ser surdo e não há uma essência acima de qualquer atravessamento cultural; há, sim, representações, códigos, sentimentos compartilhados por um grupo de pessoas, todos forjados nas experiências vivenciadas por sujeitos surdos diferentes e em espaços distintos (LOPES, 2007, p. 88).
}

Considera-se que o ensino de Libras deve oportunizar aos educandos um outro olhar e um nova representação social sobre o sujeito surdo, partindo de uma visão holística, da integralidade do ser e da singularidade existencial.

\title{
Prática Educativa: a metodologia como caminho na aprendizagem
}

Em relação à prática educativa da professora de Libras os entrevistados inferiram as seguintes ancoragens em suas RS: metodologia diferenciada e didática, prática estimuladora e aulas criativas, dialogadas e participativas.

\section{a) Metodologia diferenciada e didática}

Os estudantes objetivaram suas representações destacando o uso da professora de uma metodologia diferenciada da tradicional, sendo didática e de fácil aprendizagem.

Porque ela usa uma metodologia diferenciada com a gente (E2).

Porque ela utiliza metodologias que aprendemos e compreendemos fácil, usa maneiras simples, não deixa a aula monótona, usa métodos diferentes a cada dia (E19) 
Pois se utiliza de mecanismos diferenciados para o processo de aprendizagem, exemplos: utilização de slides, filmes, apostilas, entre outros garantindo uma assimilação eficaz em relação ao educando (E14)

Porque ela tenta repassar o conteúdo de várias formas, usando diversos métodos que melhor se encaixe com o raciocínio do aluno (E21).

\section{b) Prática Estimuladora}

E 6 ancora a prática docente como estimuladora, objetivado pelo fato de que"estimula para novos aprendizados, contribuindo para o desenvolvimento social e pessoal" (E6).

\section{c) Aulas criativas, dialogadas e participativas.}

As objetivações dos estudantes corroboram as ancoragens de serem as aulas da professora de Libras criativas, dialogadas e participativas.

Porque usa como metodologia: aulas práticas e criativas isso é de suma importância para nossa formação (E13)

Utiliza recursos necessários para melhor compreensão dos textos. Além de realizar aulas práticas que possibilita a interação dos alunos.(E26)

Porque ela deixa a aula bem livre e interativa com os alunos (E4)

Nos deixa mais à vontade, faz roda de conversa e chama a comunidade surda para participar da aula, para que possamos interagir e entender a importância do uso da Língua (E2)

Os entrevistados, então, objetivam essas representações ao informar que a educadora utiliza de mecanismos diferenciados para o processo de aprendizagem, estimulando aos educandos a aprender, por meio de aulas criativas, dialógicas e participativas que despertam o interesse pela temática em estudo

Falas que corroboram o pensamento de Tardif (2002, p. 234) de que o fazer docente "não é somente um espaço de aplicação de saberes provenientes da teoria, mas um espaço de produção de saberes específicos oriundos dessa mesma prática" (TARDIF, 2002, p. 234).

De acordo com Freire (1980b, p. 81) “a educação é continuamente refeita pela práxis". Desta forma, faz necessário, no processo de ensino, o uso de metodologias que estejam relacionadas à necessidade dos educandos, no âmbito social, identitária, cultural, linguística, cognitiva, humanizadora entre outras (GIUSEPPE, 1981).

Por fim, a prática educativa da professora de Libras firma-se em uma base epistêmica freireana e se materializa em um ensino reflexivo, crítico, dialógico e humanizador. Já que, "ensinar não é transmitir conhecimento, mas criar as possibilidades para a sua própria produção ou a sua construção" (FREIRE, 2007, p. 47).

\section{CONSIDERAÇÕES FINAIS}

Entre os resultados destacamos que em relação às RS sobre a disciplina Libras foram expressas as seguintes palavras: excelente; dinâmica; inovadora; reflexiva; boa; Praxiológica; coletiva; estimuladora; produtiva; interessante, entre outras. 
As representações dos educandos sobre a ação educativa da professora evidenciaram existir: a) Princípio dialógico através da materialização da Roda de Conversa e no diálogo em Libras, b)Ensino Reflexivo por meio de vídeo, textos, poesias, filmes e slides; c) Praxiologia com base na Representatividade e movimento surdo, o protagonismo e militância surda, por meio do reconhecimento da Libras como elemento formativo na identidade surda e d) Ambiente de alteridade a partir do respeito entre os sujeitos, entre seus saberes sendo práticas educativas humanizadoras, acolhedoras e amorosas.

Após as análises das RS concluímos que a disciplina Libras apresenta os seguintes princípios formativos Freireanos: o diálogo, a amorosidade, o respeito à diferença, a alteridade, a criticidade e a práxis, favorecendo a inclusão do aluno surdo e realizando a interface entre a Educação do campo e a Educação Especial.

\section{REFERÊNCIAS}

ALVEZ-MAZZOTTI, A. J; MAGALHÃES, E. M. M; MAIA, H. Representações sociais de trabalho docente: significados atribuídos a dedicação por professores das séries iniciais e seus formadores. Disponível: $<$ http://www.estudosdotrabalho.org/anaisvii-7-seminario-trabalhoret-2010>. Acesso em: 10. 04. 2010.

BARDIN, L. Análise de conteúdo. Lisboa, Portugal: Edições 70, 2010

BRASIL. Ministério da Educação. Conselho nacional de educação. Câmara de Educação Básica. Resolução $\mathrm{n}^{\circ}$ 2, de 28 de abril de 2008b. Estabelece diretrizes complementares, normas e princípios para o desenvolvimento de políticas públicas de atendimento da Educação Básica do Campo. Disponível em: 〈http://www.mec.gov.br>. Acesso em: 11 jan.2019.

BRASIL. Ministério da Educação. Política nacional de educação especial na perspectiva da educação inclusiva. Brasília: MEC, 2008a. Disponível em: <http://www.mec.gov.br>. Acesso em: 11 jan.2019.

BRASIL. Resolução CNE/CEB $\mathrm{n}^{\circ} 1$, de 3 de abril de 2002. Institui diretrizes operacionais para a educação básica nas escolas do campo. Diário Oficial da União, Brasília, Seção 1, p. 32, 9 abr. 2002. Disponível em: <http://www.mec.gov.br>. Acesso em: 11 jan.2019.

BRASIL, Lei $n^{o}$ 10.436, de 24 de abril de 2002. Dispõe sobre a língua brasileira de sinais - Libras e dá outras providências. Disponível em: <http://www.planalto.gov.br/ccivil_03/leis/2002/110436.htm>. Acesso em 29 Abril 2019. 
BRASIL. Decreto n. 5.626 de 22 de dezembro de 2005. Regulamenta a Lei n. 10.436, de 24 de abril de 2002, que dispõe sobre a língua brasileira de sinais - Libras. Disponível em: <www.planalto.gov.br/ccivil_03/_ato2004.../2005/decreto/d5626.htm>. Acesso em: 08 fev. 2019.

CHIZZOTTI, A. Pesquisa em ciências humanas e sociais. 10. ed. São Paulo: Cortez, 2009.

COUTINHO, M. da P.L.; NÓBREGA, S. M.; CATÃO, M. de F.F.M. Contribuições Teórico-Metodológicas acerca do uso dos instrumentos projetivos no campo das Representações Sociais. In: COUTINHO, M. da P.L. (org.) Representações sociais: abordagem interdisciplinar. João Pessoa: Editora Universitária, 2003.

FREIRE, Paulo. Pedagogia da autonomia: saberes necessários à prática educativa. 36. ed. São Paulo: Paz e Terra, 2007.

Pedagogia da tolerância. São Paulo: UNESP, 2004.

. Educação como prática da liberdade. Rio de Janeiro: Paz e Terra, 1994.

Professora sim, tia não: cartas a quem ousa ensinar. São Paulo: Ed. Olho d'Água, 1993.

. Pedagogia do Oprimido. 17. ed. Rio de Janeiro: Paz e Terra, 1987.

Educação e mudança. 4. ed. Rio de Janeiro: Paz e terra, 1981.

. Extensão ou comunicação?. 5. ed. Rio de Janeiro: Paz e Terra, 1980a.

Conscientização. Teoria e prática da libertação: uma introdução ao pensamento de Paulo Freire. 3. ed. São Paulo: morais, 1980 b.

GIUSEPPE, Imídio Nérci. Metodologia do ensino: Uma introdução 2. ed. Atlas, 1981.

LOPES, M. C. Surdez e Educação. Belo horizonte: editora Autêntica, 2007.

LUDKE, M.; ANDRÉ, M. Pesquisa em educação: abordagens qualitativas, SP EPUD, 1986. 
MOSCOVICI, S. A representação social da psicanálise. Rio de Janeiro: Zahar, 1981.

Representações sociais: investigações em psicologia social. 5 ed. PetrópolisRJ: Vozes, 2009.

NASCIMENTO, I. P. Articulações sobre o campo das representações sociais. In: ORNELLAS, M. L. S. Representações sociais e educação: letras imagéticas. Salvador: EDUFBA, 2013.

RANGEL, M. A pesquisa de representação social como forma de enfrentamento de problemas socioeducacionais. Aparecida São Paulo: Ideias e Letras, 2004.

TARDIF, M. Saberes docentes e formação profissional. Tradução de Francisco Pereira. Petrópolis: Vozes, 2002.

SANTOS, Lara Ferreira dos; CAMPOS, Mariana de Lima Isaac Leandro. O ensino de Libras para futuros professores da educação básica. IN: LACERDA, C.B.F; SANTOS, L.F. (org). Tenho um aluno surdo, e agora?. EdUfscar, 2013. p. 237-250.

Recebido: $10 / 04 / 2020$

Aprovado: 12/06/2020 